\title{
Is technology-enhanced feedback encouraging for all in Finnish basic education? A person-centered approach
}

\section{Oinas, Sanna}

\section{8-12}

Oinas , S , Vainikainen, M-P \& Hotulainen, R 2018 , ' Is technology-enhanced feedback encouraging for all in Finnish basic education? A person-centered approach ', Learning and Instruction , vol. 58 , pp. 12-21 . https://doi.org/10.1016/j.learninstruc.2018.05.002

http://hdl.handle.net/10138/322148

https://doi.org/10.1016/j.learninstruc.2018.05.002

cc_by_nc_nd

acceptedVersion

Downloaded from Helda, University of Helsinki institutional repository.

This is an electronic reprint of the original article.

This reprint may differ from the original in pagination and typographic detail.

Please cite the original version. 


\section{IS TECHNOLOGY-ENHANCED FEEDBACK ENCOURAGING FOR ALL?}

Final Draft: Oinas, S., Vainikainen, M.-P., \& Hotulainen, R. (2018). Is technology-enhanced feedback encouraging for all in Finnish basic education? A person-centred approach. Learning \& Instruction, 58, $12-21$.

\section{Introduction}

Receiving online feedback from the teacher via a computer or smartphone has become a daily practice in several countries. Both pupils and parents find these platforms useful but also frustrating (Palts \& Kalmus, 2015). In Finland, the majority of basic education schools use platforms as a convenient method to provide instant feedback related to learning and behaviour during lessons just by clicking predefined options. A recent study by (reference deleted to maintain the integrity of the review process) showed that in this context, technology-enhanced feedback was delivered unequally to pupils. This study aims to deepen the understanding of current practices of technology-enhanced feedback by looking at different types of feedback profiles from individual pupils' perspective. Due to shortage of earlier research, it is important to study how new technologies are currently used for supporting learning between different learner subgroups but also to detect if technology-enhanced feedback practices are in line with inclusive schools for all policies implemented at least in Europe and USA (ESSA, 2015; Taub, McCord \& Ryndak, 2017; Telhaug, Mediås \& Aasen, 2006). Both theory and curriculum emphasise that one of the most important goals of teaching pupils with special education needs is to prevent future problems by offering encouraging feedback (Hughes, 2010; NBE, 2014; Taub, et al., 2017). Behaviour problems may be the reason for special education needs, and there are strong reasons to assume that pupils with special needs receive more negative feedback related to behaviour problems. If this is the case, encouraging feedback should be provided to balance the situation (Moore Partin, Robertson, Maggin, Oliver \& Wehby, 2010). To enhance the motivation and learning of a pupil, feedback should be emotionally encouraging and targeted to the learning process rather than the learner as a person (Dweck \& Master, 2009; Hughes, 2010; Rowe 2010; Tennant, 


\section{IS TECHNOLOGY-ENHANCED FEEDBACK ENCOURAGING FOR ALL?}

Demaray, Malecki, Terry, Clary \& Elzinga, 2015), which is usually the situation when assessing behaviour.

There are several studies related to the effects of technology-enhanced feedback on learning outcomes (eg, Tanes, Arnold, King, \& Remnet, 2011) and interest toward learning analytics is growing (Tempelaar, Rienties \& Giesbers, 2015), However, there is a gap in theory about technology-enhanced feedback related to observed learning and behaviour during the lessons (Palts \& Kalmus, 2015), especially when different learners are considered.

The data of this study consist of 211003 separate feedback notes analysed partly in our previous study (reference deleted to maintain the integrity of the review process). Feedback notes were delivered by 704 teachers to 7811 pupils via a technology-enhanced platform in the school year 20142015. Previous analyses made both by parametric and non-parametric methods showed that feedback is distributed unevenly to girls and boys regarding the amount and the content of feedback, indicating the possibility of differentiated profiles. Now we have also included information of individual support needs and absences to analyses. A latent class analysis by Reinke, Herman, Petras and Ialongo (2008) showed that academic difficulties were the reason for special education needs for girls, but for boys, behaviour problems also explained the placement in a subgroup of special education needs. Therefore, we expect the feedback, which is in our focus, to be different for girls and boys. Gendered analyses are also necessary due to uneven distribution of girls and boys in the group of children with special education needs (Statistics Finland, 2016) and, gender differences in learning outcomes and attitudes (OECD, 2018). We aim to identify subgroups of pupils with different feedback profiles in the context of the Finnish three-tier support model (Vainikainen, 2014), which is implemented to prevent problems by providing individual support whenever there is a need. We use latent profile analysis (LPA) to reveal student-level differences instead of comparing means (see Shenke, Ruzek, Lam, Karabenick \& 


\section{IS TECHNOLOGY-ENHANCED FEEDBACK ENCOURAGING FOR ALL?}

Eccles, 2018). The target is to assess whether pupils with or without support needs are treated equally according to technology-enhanced feedback based on the concept of school for all. Theoretically this paper focuses on the role of encouraging feedback and emotional support in enhancing learning highlighted both by pupils and theory (e.g. Ferguson, 2011; Hattie \& Timperley 2007; Rowe, Fitness \& Wood, 2013; Tennant, et al., 2015).

\subsection{Feedback and technology}

New online technologies have been adopted rapidly both in general and special education. According to a recent meta-analysis, online tools can support learning of individuals with special needs (Cumming \& Rodriquez, 2017), and technology-enhanced feedback can promote learning (Yuan \& Kim, 2015). In this study, feedback is defined from the formative assessment perspective, where the purpose of the feedback is to provide information on how to work towards a desired goal from the current level of performance or behaviour (Hughes, 2010). Studies about technology-enhanced feedback typically focus on the presence, timing or content of feedback (Kefalidou, 2017; Yuan \& Kim, 2017). This study focuses on the content, providing new knowledge about the given technologyenhanced feedback related to learning and behaviour during the lessons.

A recent Estonian study describes the benefits and disadvantages of technology-enhanced teacher feedback (Palts \& Kalmus, 2015) by showing that technology enhances home-school collaboration although parents perceived that messaging may reduce pupils' responsibility to take care of their own duties. Similar critique has been published in New York Times (Hoffman, 2008) indicating the need for evaluating the technology-enhanced feedback practices.

Studies about feedback often describe interventions where feedback is provided to improve learning results (e.g. Hattie \& Timperley, 2007; Kluger \& DeNisi, 1996) or behaviour (StantonChapman, Walker, Voorhees \& Snell, 2016). According to Hattie and Timperley (2007), feedback can 


\section{IS TECHNOLOGY-ENHANCED FEEDBACK ENCOURAGING FOR ALL?}

be positive or negative, and both may enhance learning outcomes and motivation (see also Ryan $\&$ Deci, 2009). However, both types of feedback may also be harmful if feedback targets the learner as a person instead of focusing on the learning process (Dweck \& Master, 2009; Rowe, Fitness \& Wood, 2014). Feedback should be designed carefully, as feedback based on social comparison with peers can be perceived either positively or negatively and thus have an influence on whether pupils adopt a learning-approach or learning-avoidance orientation (Pekrun, Cusack, Murayma, Elliot and Thomas 2014). On the other hand, learning may be fostered by warning of possible errors (Acuna, GarciaRodiccio, \& Sanchez, 2010; Loibl \& Rummel, 2014), although feedback describing mistakes may promote learning avoidance (Shin et al., 2017). In fact, Kluger and DeNisi (1996) found, based on 3000 studies, that more than one out of three feedback interventions influenced learning outcomes negatively.

University students appreciate both positive and negative feedback if they perceive it useful for improving their studies (Rowe, et al., 2014). In contrast, students who easily feel that they have failed or who feel guilt over undone work consider feedback as irrelevant as they fear receiving negative feedback (Rowe et al., 2014). Previous experiences of success and failure shape the way the given feedback is interpreted (Kluger \& DeNisi, 1996). Hughes (2010) warned that pupils at risk of academic failure usually avoid corrective feedback as they perceive it as a negative assessment toward themselves. The variation in feedback practices may be explained by different behaviour of teachers, as there are still teachers who perceive technology as a threat (Gao, Yan, Wei, Liang \& Mo 2017). Furthermore, teachers' perceptions of pupils' capability to learn may have impact on evaluation (Mullola, 2012). 


\section{IS TECHNOLOGY-ENHANCED FEEDBACK ENCOURAGING FOR ALL?}

\subsection{Feedback as encouragement in school for all}

Inclusion has been the focus of special education since the 1980s, and the aspiration of inclusion was part of the UNESCO Salamanca statement on special education in 1994 (UNESCO, 1994). According to a broad definition of inclusive education, every child is a unique individual and has the right to be accepted to school just as he or she is (Hotulainen \& Takala, 2014). The idea of school for all is not, however, the reality in Finland. Despite inclusion, over four percent of Finnish pupils in basic education are still transferred into segregated classrooms for example based on inappropriate behaviour or disability (Saloviita \& Schaffus, 2016).

The focus of inclusion is to provide early support to prevent future problems, for example, school dropout (Maggin, Wehby, Warner \& Brooks, 2016; Taub, et al., 2017). Hughes (2010) writes that the goal of feedback for pupils with special needs is to reduce the at-risk status of these pupils. She continues that more research is needed to evaluate whether pupils at risk benefit from teacher praise as encouragement (Hughes, 2010).

Emotional or behavioural problems occur in most adolescents, but with appropriate support, these problems can be solved (Maggin et al., 2016). Teachers' verbal encouragement that illustrates a desired behaviour has a connection to the positive behaviour of first graders (Spivak \& Farran, 2012). Emotional support as a form of feedback by the teacher is related to better achievements, school adjustment and fewer problems in pupils (Tennant et al., 2015). In their study, Tennant and colleagues (2015) recognised several gender differences in how pupils perceived and took advantage of emotionally supportive feedback from their teachers. A recent study also showed that teachers' unfair classroom practices are connected to variation of emotional support provided by teachers as perceived by pupils (Shenke, et al., 2018). Supportive feedback increases students' perceived motivation and decreases anxiety and stress (Rowe, 2010). Providing positive feedback through technology may be 


\section{IS TECHNOLOGY-ENHANCED FEEDBACK ENCOURAGING FOR ALL?}

essential if one has a tendency to be anxious (Hinton, Fischer \& Glennon, 2012). However, Alcott (2017) argues that teachers put more effort into enhancing educational progress by providing encouragement for high performing students, although it would be the most beneficial for averagely performing students.

Encouraging feedback goes hand in hand with creating a positive learning environment, as it also increases school adjustment, well-being (Reddy, Rhode \& Mullhal, 2003) and engagement (Klem \& Connell, 2004). A large-scale study showed that support from the teacher has an impact on the development of better self-esteem in $6^{\text {th }}-8^{\text {th }}$ graders (Reddy et al., 2003). Even students at the university level need encouraging feedback to balance critique and to maintain confidence (Ferguson, 2011). However, Harris, Brown and Harnett (2014) reported that teachers $(\mathrm{N}=612)$ evaluated supportive feedback as being less important. Unfortunately, teachers may also use unprofessional methods, as for example label the pupil on the basis of personal qualities, or show frustration or hostile emotions with "problematic" pupils (Kourkoutas \& Giovazolias, 2015), which jeopardises any perceived emotional support. There is a clear evidence that a pupil with support needs and behaviour problems may end up dropping out of school and even into a cycle of failure without individual encouraging support (Maggin, et al., 2016).

According to Saloviita and Schaffus (2016), the majority of teachers in Finland and Germany are worried about the extra work in teaching and writing pedagogical documents caused by inclusive education. This situation has led gradually to the availability of a range of technical solutions that provide templates and menus from which teachers can choose, for example, appropriate feedback options. Severinsson (2016) states that the form and the content of the documentation templates used in special education may produce a list of problems instead of focusing on solutions. Therefore, it may also be that the predefined options in an online platform generate the given feedback. 


\section{IS TECHNOLOGY-ENHANCED FEEDBACK ENCOURAGING FOR ALL?}

In Finland, after adopting inclusion, the ability to provide qualified research-based teaching is emphasised in teacher education (Tirri \& Laine, 2017). However, the psychological needs of pupils in special education are not supported enough (Thuneberg, 2007). Recently graduated primary school teachers were satisfied with the competence gained through teacher training regarding planning instruction and reflecting on professional development; however, they perceived that they needed more competence to provide support for pupils with special education needs (Saloviita \& Tolvanen, 2017).

\subsection{Research questions}

Encouraging feedback about the learning process should be provided to all pupils, especially for pupils with special education needs to enhance their learning results and well-being (Hughes, 2010; NBE, 2014). It seems that technology-enhanced feedback is perceived contradictory (Hoffman, 2008; Palts \& Kalmus, 2015) and it is suggested that girls and boys themselves perceive teachers' encouraging feedback differently (Shenke, et al., 2018; Tennant, et al., 2015;). The use of feedback platforms may vary as there are usually no pedagogical guidelines for the use in the curriculum and not all teachers consider supportive feedback to be important (Harris, et al., 2012). Recently, Taub and colleagues (2017) wrote that more research is needed to evaluate teachers' practices to ensure equal opportunities for inclusive education for all. Therefore, the research questions and hypotheses are: RQ1: What kind of technology-enhanced feedback profiles can be identified in the Finnish context, when analyses are done separately for girls and boys?

H1: It is expected that latent profile analysis (LPA) will reveal several hidden groups from the data (Oberski, 2016), as large sample sizes usually reveal number of profiles (Marsh, Lüdtke, Trautwein \& Morin, 2009). It is expected that profiles vary between genders, as boys are shown to have more negative feedback (reference deleted to maintain the integrity of the review process). 


\section{IS TECHNOLOGY-ENHANCED FEEDBACK ENCOURAGING FOR ALL?}

RQ2: Is technology-enhanced feedback equally encouraging for all?

H2: An idea of school for all is related to supporting diverse pupils equally (Tirri \& Laine, 2017). In addition, encouraging feedback is highlighted in curriculum (NBE, 2014) and literature (eg. Hughes, 2010). Therefore, we expect that all the pupils are equally encouraged.

RQ3: Can feedback profiles be explained by membership in a certain teaching group?

H3: It is expected that belonging to a certain feedback subgroup may partly be explained by a teacher's behaviour. Besides technology, teachers provide feedback face-to-face (Palts \& Kalmus, 2015) and some teachers still perceive technology as a threat (Gao, et al., 2017).

\section{Methods}

\subsection{Context of the study: The Finnish three-tiered support model}

Studying in Finnish basic education is free of charge and less than $2 \%$ of pupils study in private schools (Statistics Finland, 2016). Nowadays, instead of the earlier division into general and special education, support is provided for all pupils based on the 3-tier support model (Vainikainen, 2014). Tier 1, general support, means that all pupils may have, for example, remedial teaching, individual guidance, differentiation and part-time special education whenever the need arises. Tier 2, intensified support, is provided when the general support is insufficient. Intensified support targets preventing bigger learning or behaviour problems and ideally, after a period of intensified support, the pupil may move back to Tier 1. Intensified support must always be supplied before a decision to move to on Tier 3, special support, is made (Vainikainen, 2014). Moving from tier to tier needs documentation and home-school collaboration.

After the reform of special education, the number of pupils in Tier 3 has decreased and the number of pupils in Tier 2 has increased. In the latest statistics, 16 percent of all Finnish pupils 


\section{IS TECHNOLOGY-ENHANCED FEEDBACK ENCOURAGING FOR ALL?}

received support either in Tier 2 or 3. Of these pupils 65-70 percent were boys (Statistics Finland, 2016). The teaching of pupils receiving three-tier support is provided in both mainstream teaching groups and segregated special education classrooms. This study aims to evaluate whether the pupils in different tiers of support are equally encouraged.

\subsection{Participants and procedure}

The data in this study consisted of 211003 separate feedback actions, called lesson notes. They were registered in the most commonly used technology-enhanced platform in one middle-sized municipality in Southern Finland. The data were drawn directly from the platform with the permission of the municipality and consisted of all feedback actions given in the municipality during the school year 2014-2015. The data covered 7811 pupils (girls 49.2\%) and 704 teachers in basic education. The data included 38 different schools, which had altogether 715 separate teaching groups. The data is evaluated from pupils' and teachers' perspectives after observing the effects of school and class level differences. Information on individual support needs according to the three-tiered support model was merged into the data in order to evaluate whether the treatment of pupils with special needs is equally encouraging according to technology-enhanced feedback. In the municipality providing the data, as much as 22.4 percent of pupils needed Tier 2 or Tier 3 support, even though the corresponding percentage on the national level is 16 (Statistic Finland, 2016). Boys seemed to need twice as much support as girls. Pupils with no support needs and support needs in Tier 1 were categorised into the same group, as every pupil can receive support when needed and legislation does not give specific instructions on categorisation of pupils into Tier 1 . Therefore, Tier $0 / 1$ is used from now on (Table 1).

Table 1. Pupils in grade-level groups with provided support based on 3-tier model.

\begin{tabular}{lrrrrrrr}
\hline & & Tier-0/1 & & Tier-2 & & Tier-3 & \\
\hline & Girls & Boys & Girls & Boys & Girls & Boys & Together \\
Grades 1-2 (7-8 years old) & 744 & 576 & 68 & 128 & 33 & 109 & 1658 \\
Grades 3-6 (9-12 years old) & 1417 & 1207 & 132 & 234 & 103 & 290 & 3383 \\
& & 9 & & & & &
\end{tabular}




\section{IS TECHNOLOGY-ENHANCED FEEDBACK ENCOURAGING FOR ALL?}

\begin{tabular}{lrrrrrrr} 
Grades 7-9 (13-15 years old) & 1113 & 1007 & 118 & 203 & 112 & 217 & 2770 \\
\hline Total & 3274 & 2790 & 318 & 565 & 248 & 616 & 7811 \\
$\%$ & 41.9 & 35.7 & 4.1 & 7.2 & 3.2 & 7.9 & 100 \\
\hline
\end{tabular}

\subsection{Measures}

The technology-enhanced feedback, called lesson notes, consisted originally of eleven predefined options that teachers could easily click on to give feedback. In the municipality providing the data, the options were identical for all teachers, and the teachers could send notes as often as they considered it necessary. All the options were categorised under three titles based on the content of the feedback originally in our previous study (reference deleted to maintain the integrity of the review process). The reliability of the summed variables was confirmed by Cronbach's alpha based on standardised items and two-item Spearman-Brown coefficient. The options forgotten homework, forgotten supplies and undone duty (e.g. forgotten signature/permission from parents) were classified under the title Forgotten matters $(\alpha=0.752)$. The options inappropriate behaviour during the lesson, inappropriate language, smoking, exiting the schoolyard and using a mobile phone without permission were classified under the title Behaviour problems $(\alpha=0.639)$ and were considered negative feedback. The options active attendance and positive feedback were classified as Teacher praise $(\rho=0.569)$ and were considered encouraging feedback. There was also the option to give a note of absence from the lesson.

\subsection{Data analyses}

First, the effects of school and class level for each dependent variables were observed in order to create an overview to the data. This was conducted by calculating the intraclass correlation for threelevel regression model with Maximum Likelihood estimation. Descriptive statistics were then calculated separately for the participants and feedback categories separately. The large variation of 


\section{IS TECHNOLOGY-ENHANCED FEEDBACK ENCOURAGING FOR ALL?}

minimum and maximum values of the means gave an indication of pupils being treated differently. Therefore, we conducted latent profile analysis (LPA), as a useful method for observing populationwide phenomena and for revealing hidden subgroups based on participants characteristics, not based on the variables measured (Williams \& Kibowski, 2016). This was chosen as a more flexible method than cluster analyses (Oberski, 2016) as LPA is a person-centred approach, where the final number of the hidden patterns is determined through a comparison of fit indices (Williams \& Kibowski, 2016). We used a Bayesian information criterion (BIC), the Vuong-Lo-Mendell-Rubin likelihood ratio test (VLMR), and an entropy value to determine the best model fit. The analyses were conducted separately for boys and girls. The information on absences was included in the analysis. The number of subgroups best describing the data were chosen, and finally, the latent factor scores of the identified subgroups were coded into the data. Statistical differences between the identified profiles were calculated with one-way ANOVA.

To answer the second research question about whether pupils needing extra support were treated in an equally encouraging way, the values of the mean differences between the latent factor scores of the subgroups and the dummy coded variable of the individual support need of pupils were analysed using ANOVA and confirmed with Mann-Whitney U-tests due to small groups. Although there was originally information on three different levels of support, the support need was dummy coded (pupils in Tier $0 / 1=0$ and pupils in Tiers $2 / 3=1$ ) to avoid too small groups.

Finally, the number of different feedback profiles in a single classroom, and the number of teaching groups per profile were computed in order to evaluate whether there were teachers who gave feedback for all the pupils in a similar way in the classroom. 


\section{IS TECHNOLOGY-ENHANCED FEEDBACK ENCOURAGING FOR ALL?}

\section{Results}

First, we detected if there were school and class level effects on main independent variables. Depending on the variable in question, school explained from 5 to 36 and class from 16 to 28 percent of variance (appendix 1). The reader needs to be aware of these statistics when thinking of the generalisability of the results.

Descriptive statistics (means, standard deviations, minimum and maximum values) for boys and girls organised into three-tiered support groups are presented in Table 2 . The values reveal a large variation between the groups and feedback variables. Boys had more technology-enhanced feedback related to Forgotten matters and Behaviour problems compared to girls. However, it seems that girls and boys received an equal amount of Teacher praise, although pupils in Tier 0/1 received more Teacher praise compared to others. According to these values, there was also variation in absences between different Tiers of support, but not between genders. It is also to be noticed that in each category there are pupils who received zero feedback notes. Due to these preliminary findings, a LPA was conducted.

Table 2. Descriptive statistics of technology-enhanced feedback by groups.

\begin{tabular}{|c|c|c|c|c|c|c|c|}
\hline & & \multicolumn{3}{|c|}{ Girls } & \multicolumn{3}{|c|}{ Boys } \\
\hline & & Tier $0 / 1$ & Tier 2 & Tier 3 & Tier $0 / 1$ & Tier 2 & Tier 3 \\
\hline & & $\mathrm{N}=3274$ & $\mathrm{~N}=318$ & $\mathrm{~N}=248$ & $\mathrm{~N}=2790$ & $N=564$ & $\mathrm{~N}=616$ \\
\hline \multirow[t]{2}{*}{ Teacher praise } & $\mathrm{M}(\mathrm{SD})$ & $19.18(27.32)$ & $12.1(16.09)$ & $9.98(16.81)$ & $17(22.8)$ & 11.88 (16.6) & $9.28(14.45)$ \\
\hline & $\min -\max$ & $0-179$ & $0-75$ & 0-108 & 0-159 & 0-94 & $0-80$ \\
\hline$*$ pupils $\%$ & zero/below/above & $28.6 / 39 / 38$ & $29.2 / 37 / 32$ & $42,7 / 27 / 29$ & $28.4 / 38 / 33$ & $30.5 / 36 / 32$ & $40 / 29 / 30.5$ \\
\hline \multirow[t]{2}{*}{ Forgotten matters } & $\mathrm{M}(\mathrm{SD})$ & $5.71(9.04)$ & $12.89(16.23)$ & 7.39 (12.87) & $10.65(13.71)$ & $18.79(20.52)$ & $11.41(19.02)$ \\
\hline & $\min -\max$ & 0-102 & 0-99 & 0-99 & 0-129 & $0-131$ & $0-165$ \\
\hline$*$ pupils $\%$ & zero/below/above & $28.4 / 40 / 27$ & $17 / 46.5 / 33$ & $39 / 34 / 25.4$ & $18.4 / 54 / 25$ & $14.4 / 45.5 / 37$ & $32.3 / 37 / 29$ \\
\hline \multirow[t]{2}{*}{ Behaviour problems } & $\mathrm{M}(\mathrm{SD})$ & $.5(2.05)$ & $1.43(3.79)$ & $.95(3.33)$ & $2.48(6.19)$ & $5.08(9.67)$ & 3.19 (7.68) \\
\hline & $\min -\max$ & 0-32 & $0-36$ & $0-27$ & $0-90$ & $0-77$ & $0-55$ \\
\hline$*$ pupils $\%$ & zero/below/above & $84.3 / 5 / 8$ & $69.5 / 9 / 16$ & $75.4 / 9 / 13$ & $56 / 21 / 18$ & $43.3 / 30.5 / 22$ & $61 / 18.5 / 17$ \\
\hline
\end{tabular}




\section{IS TECHNOLOGY-ENHANCED FEEDBACK ENCOURAGING FOR ALL?}

$\begin{array}{llrrrrrr}\text { Absences } & \text { M (SD) } & 48.19(52.34) & 60.4(69.88) & 73.02(92.85) & 49.51(51.03) & 60.46(68.88) & 59.31(72.97) \\ & \text { min-max } & 0-728 & 0-383 & 0-831 & 0-727 & 0-537 & 0-701\end{array}$

* Percentages of pupils who did not receive feedback (zero) and who received feedback either below or above average.

\subsection{Latent profiles of girls and boys receiving technology-enhanced feedback}

Latent profile analyses (LPA) were conducted separately for boys and girls using the feedback variables (Teacher praise, Forgotten matters, Behaviour problems and Absence) to identify hidden patterns of receiving technology-enhanced feedback. The fit indices of the latent profiles are displayed in Table 3.

Table 3. Fit indices of latent profiles for girls and boys.

\begin{tabular}{|c|c|c|c|c|}
\hline Number of profiles & BIC & $\rho$ VLMR & Entropy & Group sizes \\
\hline \multicolumn{5}{|c|}{ GIRLS } \\
\hline 1 & 123785.807 & & & \\
\hline 2 & 120278.273 & 0.0677 & 0.999 & 62,3778 \\
\hline 3 & 118038.083 & 0.1683 & 0.996 & $116,26,3698$ \\
\hline 4 & 116376.858 & 0.2596 & 0.974 & $3311,148,32,349$ \\
\hline 5 & 114962.692 & 0.2012 & 0.971 & $3235,123,354,102,26$ \\
\hline *6 & 113626.310 & 0.0804 & 0.975 & $3176,163,342,96,46,17$ \\
\hline 7 & 112446.445 & 0.2939 & 0.973 & $3086,90,101,162,338,46,17$ \\
\hline \multicolumn{5}{|c|}{ BOYS } \\
\hline 1 & 138345.399 & & & \\
\hline 2 & 135489.449 & 0.1695 & 0.992 & 3837,133 \\
\hline 3 & 133856.688 & 0.0000 & 0.953 & $3355,132,483$ \\
\hline 4 & 132357.708 & 0.1692 & 0.958 & $3220,237,52,461$ \\
\hline *5 & 131020.306 & 0.0083 & 0.953 & $50,221,3063,455,181$ \\
\hline 6 & 129944.416 & 0.0778 & 0.956 & $3022,171,67,215,445,50$ \\
\hline
\end{tabular}

* The profiles chosen to describe the data best.

Models from a one-class solution to a 10-class solution were run to explore the models describing the data best based on the fit indices (Table 3) and the plots. For boys, the five-class solution was chosen to be the most informative representation of how they had received technology-enhanced feedback. However, the most informative representation for girls was the six-class solution. According 


\section{IS TECHNOLOGY-ENHANCED FEEDBACK ENCOURAGING FOR ALL?}

to Marsh and colleagues, (2009), large sample sizes, such as $\mathrm{N} \approx 4000$, will result in more groups than small samples. They also state that defined groups should differ qualitatively and quantitatively, but there are no "golden rules" when selecting the right number of groups (Marsh et al., 2009). Based on the BIC indices, we would have chosen more than five and six groups. However, studying the plots showed that after these chosen solutions, there were no more qualitatively differently distributed groups, only groups smaller in size. Further, Williams and Kibowski (2016) mention that it is possible to choose a profile solution which best describes the data, even if the fit indices would recommend another solution. The loglikelihood ratio test (VLMR) and entropy values were observed to choose the best solutions (see Table 3).The average individual posterior probabilities for being assigned to a certain identified latent profile in the chosen model for girls were $0.90,0.98,0.94,0.94,0.99,0.97$ and 1.0 , and for boys $0.92,0.99,0.95,0.93,1.0$ and 0.98 .

Figures 1 and 2 present the latent profiles in the gender groups. The figures show that both girls and boys had similar patterns in receiving technology-enhanced feedback. The majority of girls (77.3\%) and boys (75.6\%) belonged in groups receiving only 0-10 feedback notes during the entire school year. However, small groups of pupils received a large amount feedback related to positive or negative behaviour. Certain groups of boys and girls received Teacher praise approximately $60-80$ times, and other small groups received feedback mainly about Forgotten matters (50 times for girls and 60 times for boys). Furthermore, some small groups received more feedback about Behaviour problems, although the group of boys received it much more often (46 times) than the group of girls (24 times). One-way ANOVA showed statistically significant differences between gender with Teacher praise $(F=1390.693, p<.001$, Cohen's $d=.12)$, Forgotten matters $(F=886.150, p<.001, d=-.41)$, Behaviour problems ( $F=3581.308, p<.001, d=-.44)$ and Absence $(F=19.503, p<.001, d=.06)$. The groups of homogenous subsets are displayed instead of post hoc test as being more informative (see 


\section{IS TECHNOLOGY-ENHANCED FEEDBACK ENCOURAGING FOR ALL?}

Table 4). Three different categories were found according to Teacher praise when the groups in homogenous subsets were observed. According to other variables, groups in homogenous subsets were displayed randomly, resulting in no clear pattern based on statistical differences between the identified profiles and variables. Therefore, we decided to define the names of the profiles based on Teacher praise.

The names of the identified subgroups were defined based on the relationship between the encouraging and negative feedback seen in the plots (Figures $1 \& 2$ ). The names chosen aim to describe the teachers' effort to encourage pupils by providing technology-enhanced feedback, as we had no data about the actual behaviour of the pupils. The groups receiving mainly Teacher praise was considered Highly encouraged. The groups receiving the second largest amount of Teacher praise were called Averagely encouraged or Averagely encouraged with forgotten matters, if the teacher had also given extensive feedback about forgotten matters. It is to be noticed that, as a result of the LPA, there were two Averagely encouraged groups for girls. Based on Teacher praise, these girls would belong in the same homogenous subset; however, they differed regarding the other variables. The groups receiving the least Teacher praise were defined as Weakly encouraged or Weakly encouraged with behaviour problems if teachers had given extensive feedback about problematic behaviour. The mean values of the feedback for the defined groups are presented in Table 4. 
IS TECHNOLOGY-ENHANCED FEEDBACK ENCOURAGING FOR ALL?

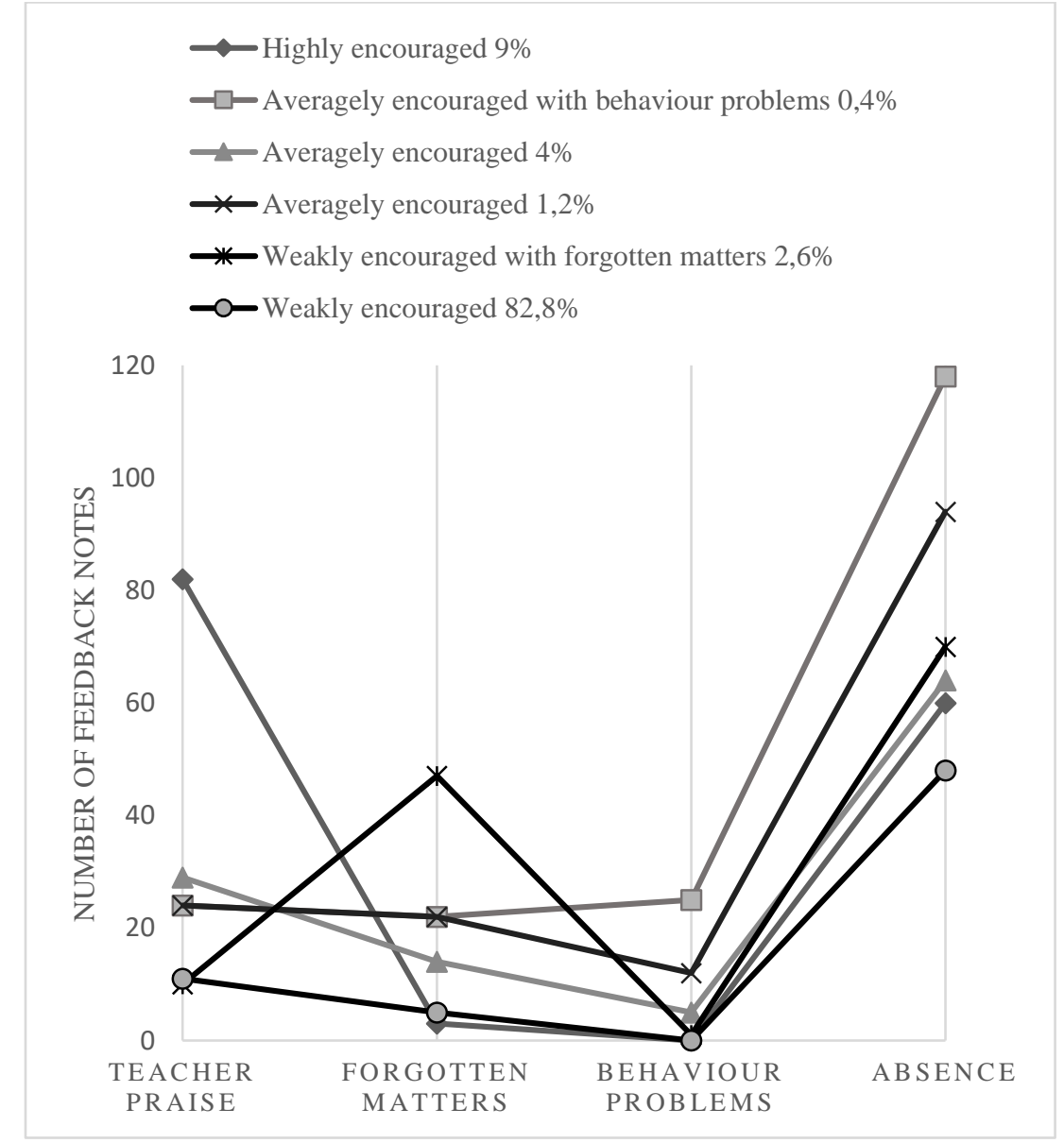

Figure 1. Subgroups of girls. $\sim$ Highly encouraged $11,4 \%$

$\rightarrow-$ Averagely encouraged with behaviour problems 1,3\%

$\checkmark$ Averagely encouraged $5,6 \%$

$\longrightarrow$ Weakly encouraged with forgotten matters $4,7 \%$

*Weakly encouraged $77,3 \%$

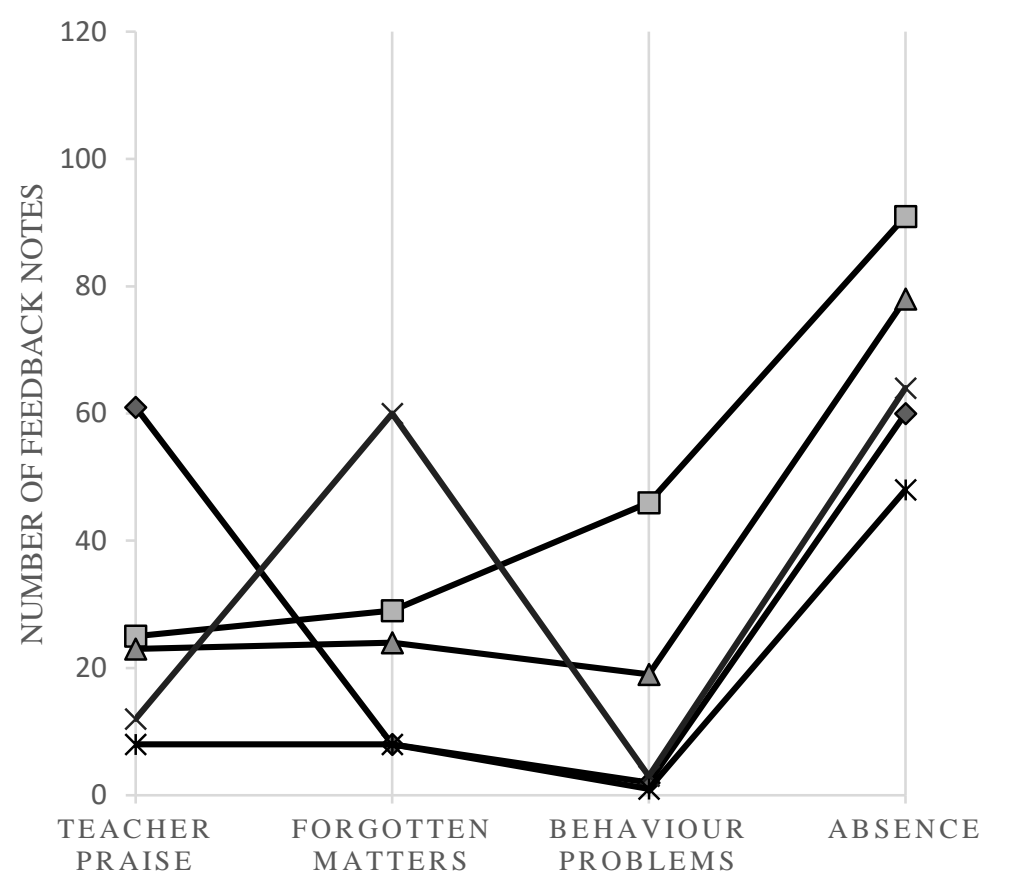

Figure 2. Subgroups of boys. 


\section{IS TECHNOLOGY-ENHANCED FEEDBACK ENCOURAGING FOR ALL?}

Table 4. Means, standard deviations and the number of teaching groups of identified subgroups.

\begin{tabular}{|c|c|c|c|c|c|c|c|c|c|}
\hline & \multicolumn{2}{|c|}{ Teacher praise } & \multicolumn{2}{|c|}{ Forgotten matters } & \multicolumn{2}{|c|}{ Behaviour problems } & \multirow{2}{*}{$\begin{array}{r}\text { Absences } \\
\mathrm{M}\end{array}$} & \multicolumn{2}{|r|}{ Teaching groups } \\
\hline & $\mathrm{M}$ & SD & $\mathrm{M}$ & SD & $\mathrm{M}$ & SD & & SD & $\mathrm{N}^{*}$ \\
\hline Highly encouraged girls $\mathrm{N}=342$ & $83.20^{\mathrm{a}}$ & 25.08 & $3.08^{\mathrm{a}}$ & 4.5 & $.27^{\mathrm{a}}$ & 61 & $59.75^{\mathrm{a}, \mathrm{b}}$ & 48.24 & 103 \\
\hline Highly encouraged boys $\mathrm{N}=455$ & $61.05^{\mathrm{a}}$ & 19.60 & $8.33^{\mathrm{b}}$ & 8.76 & $2.16^{\mathrm{b}}$ & 3.32 & $60.44^{\mathrm{a}, \mathrm{b}}$ & 43.83 & 122 \\
\hline Averagely encouraged girls $1 \mathrm{~N}=163$ & $28.95^{b}$ & 23.27 & $14.13^{c}$ & 11.56 & $4.66^{\mathrm{d}}$ & 1.5 & $64.20^{\mathrm{a}, \mathrm{b}, \mathrm{c}}$ & 50.58 & 103 \\
\hline Averagely encouraged girls $2 \mathrm{~N}=46$ & $24.24^{\mathrm{b}}$ & 20.14 & $22.50^{\mathrm{d}}$ & 22.4 & $12.00^{\mathrm{e}}$ & 2.87 & $94.35^{\mathrm{d}, \mathrm{e}}$ & 72.59 & 33 \\
\hline Averagely encouraged boys $\mathrm{N}=221$ & $23.39^{b}$ & 17.37 & $23.87^{\mathrm{d}}$ & 17.48 & $18.83^{\mathrm{f}}$ & 5.86 & $78.37^{\mathrm{b}, \mathrm{c}, \mathrm{d}}$ & 70.70 & 131 \\
\hline Averagely encouraged girls with behaviour problems $\mathrm{N}=17$ & $23.59^{b}$ & 15.71 & $21.76^{\mathrm{d}}$ & 8.06 & $24.88^{\mathrm{g}}$ & 5.11 & $118.41^{\mathrm{e}}$ & 84.87 & 16 \\
\hline Averagely encouraged boys with behaviour problems $\mathrm{N}=50$ & $24.90^{\mathrm{b}}$ & 19.42 & $28.76^{\mathrm{e}}$ & 17.1 & $46.34^{\mathrm{h}}$ & 13.01 & $91.36^{\mathrm{c}, \mathrm{d}, \mathrm{e}}$ & 88.92 & 32 \\
\hline Weakly encouraged girls with forgotten matters $N=96$ & $10.34^{\mathrm{c}}$ & 11.79 & $47.34^{\mathrm{f}}$ & 17.19 & $.78^{\mathrm{a}}$ & 1.12 & $69.85^{\mathrm{a}, \mathrm{b}, \mathrm{c}, \mathrm{d}}$ & 65.69 & 64 \\
\hline Weakly encouraged boys with forgotten matters $N=181$ & $11.99^{\mathrm{c}}$ & 12.27 & $61.28^{\mathrm{g}}$ & 21.53 & $3.51^{\mathrm{c}}$ & 4.33 & $65.49^{\mathrm{a}, \mathrm{b}, \mathrm{c}}$ & 62.00 & 98 \\
\hline Weakly encouraged girls $\mathrm{N}=3176$ & $10.53^{c}$ & 14.08 & $4.82^{\mathrm{a}, \mathrm{b}}$ & 6.36 & $.14^{\mathrm{a}}$ & .42 & $47.58^{a}$ & 57.66 & 539 \\
\hline Weakly encouraged boys $\mathrm{N}=3063$ & $7.67^{\mathrm{c}}$ & 10.41 & $8.4^{\mathrm{b}}$ & 9.65 & $1.2^{\mathrm{a}, \mathrm{b}}$ & 2.22 & $48.12^{\mathrm{a}}$ & 56.84 & 589 \\
\hline
\end{tabular}

Note 1: Groups in homogenous subsets are indicated with letters a-g. According to Teacher praise, grouping supports definition of profiles based on encouraging feedback, as Highly encouraged belong in subset a, Averagely encouraged in subset b, and Weakly encouraged in subset c. Regarding other variables, subsets were more random.

Note 2: * Number of teaching groups according to identified profiles 


\section{IS TECHNOLOGY-ENHANCED FEEDBACK ENCOURAGING FOR ALL?}

The variation in absence was from 0 to 831 lessons during the school year. However, the mean values of absence between the identified profiles ranged only from 46 to 119 lessons (see Table 4). The largest profiles for girls and boys (Weakly encouraged) had the lowest mean values of absence (46/47). The second lowest absence (59.75/60.44) was for Highly encouraged groups. Based on this data, more frequent absence seemed to be connected to receiving more feedback about Forgotten matters and Behaviour problems, although there was not necessarily causality.

\subsubsection{Pupils with special needs in identified subgroups.}

To evaluate whether the given technology-enhanced feedback is equally encouraging for all, the distributions of pupils with individual support needs in identified subgroups $(\mathrm{n}=11)$ were explored with one-way-ANOVA and Mann-Whitney U-tests. The variable of the individual support needs of pupils was dummy coded $(0=$ pupils in Tier $0 / 1,1=$ pupils in Tier $2 / 3)$. Only the statistically significant mean differences $(p<.05)$ between the subgroups and the need for support are presented in Figure 3. The largest groups of girls (82.8\%) and boys (77.3\%) did not have significant differences in this respect and therefore are not included in the figure. The results (see Appendix 2) show that there were more pupils who did not need extra support (Tier 0 or 1 support) in both Highly encouraged groups. In the groups which were Averagely or Weakly encouraged, there were more pupils needing either Tier 2 or Tier 3 support. 


\section{IS TECHNOLOGY-ENHANCED FEEDBACK ENCOURAGING FOR ALL?}

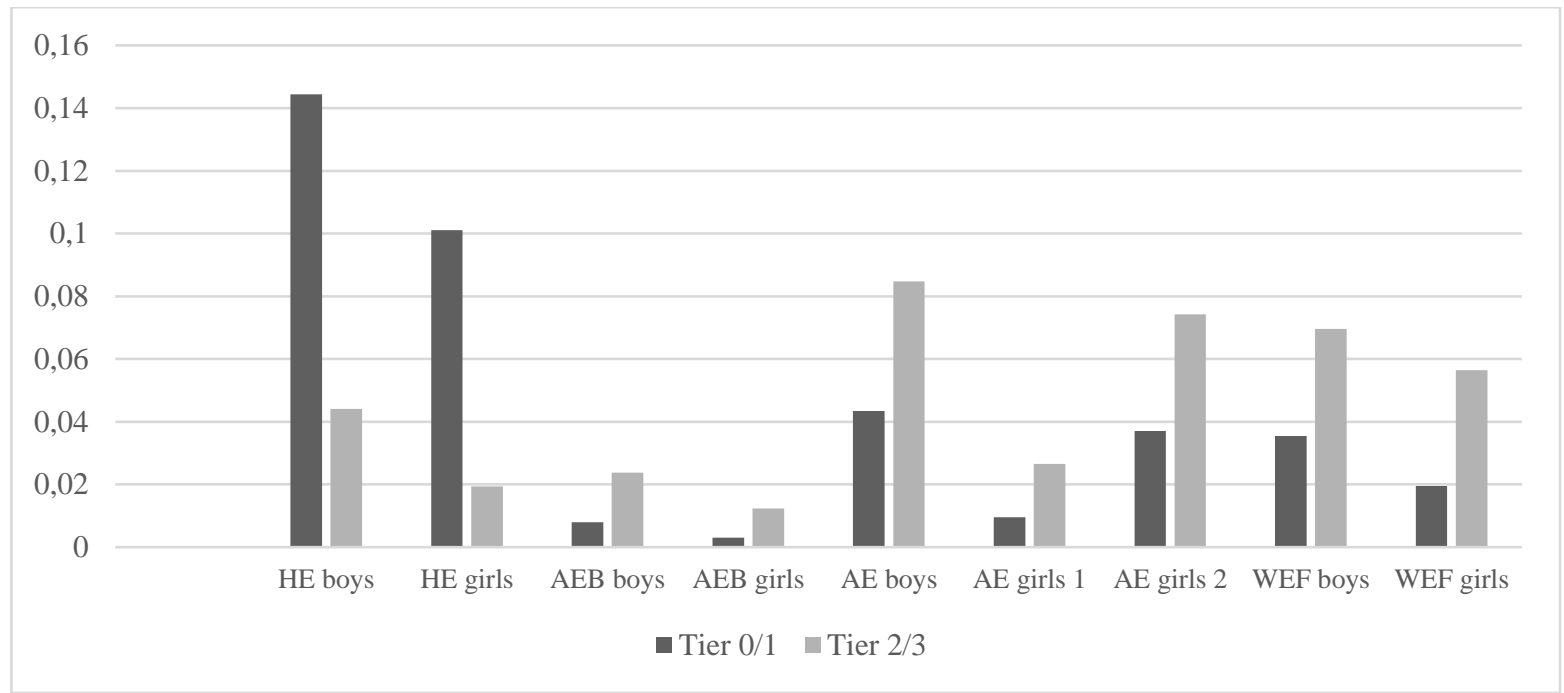

Figure 3. Values of the mean differences (0-0.16) between the latent factor scores of the subgroups and the individual support need. $\mathrm{HE}=$ highly encouraged, $\mathrm{AEB}=$ averagely encouraged with behaviour problems, $\mathrm{AE}=$ averagely encouraged, $\mathrm{WEF}=$ weakly encouraged with forgotten matters.

\subsubsection{Membership in a teaching group.}

The last research question examined whether belonging in the identified profiles is associated with a specific teacher feedback behaviour. Frequencies of the feedback profiles in a single teaching group $(\mathrm{N}=715)$ were counted in order to evaluate whether a teacher encouraged all the pupils in his/her classroom with a similar manner. Ranging from one to nine, there were on average three different feedback profiles in one teaching group. Table 4 shows that, for example, 432 Highly Encouraged girls studied in 103 separate teaching groups. Furthermore, the smallest profile (Averagely encouraged girls with behaviour problems) was not either associated with the behaviour of a single teacher as the 17 girls in this profile studied in 16 separate teaching groups. 


\section{IS TECHNOLOGY-ENHANCED FEEDBACK ENCOURAGING FOR ALL?}

\section{Discussion}

The aim of this study was to evaluate whether the pupils were equally encouraged based on the idea of school for all according to technology-enhanced feedback they received from the teacher about learning and behaviour during the lessons. Using an online platform, 704 teachers gave 211003 feedback notes to 7811 pupils during the school year 2014-2015. Schools in Finland are usually reported to be relatively homogenous concerning performance differences (Thuneberg, Hautamäki \& Hotulainen, 2015), but here, perhaps as a result of the large data including schools $(\mathrm{N}=38)$ from primary to lower secondary schools and various teaching groups from general education to segregated special education $(\mathrm{N}=715)$, the effects of school and class level differences were high. This result is interesting and shows that feedback practices vary remarkably from school to school and from teacher to teacher. In order to identify differences in individual level, latent profile analysis (LPA) was conducted. A six-group solution for girls and a five-group solution for boys best described the data. On average, pupils received feedback according to three different feedback profiles in one teaching group, explaining also the class level variation. Probability of special education needs were then evaluated according to subgroups. The relations of the identified subgroups to pupils' absence and the different feedback practices of a single teacher are discussed.

\subsection{Highly, Averagely and Weakly encouraged pupils}

The identified subgroups were named according to the extent that the teachers attempted to encourage pupils by providing praise, although some of the groups also received much feedback about behaviour problems or forgotten matters, such as homework. The data analysed in this study describe only the practices of the teachers, and therefore, we wanted to avoid using names referring to issues such as the behaviour or engagement of pupils. Hence, the subgroups were categorised as Highly, Averagely and Weakly encouraged. The Averagely encouraged groups contained a sub-category of 


\section{IS TECHNOLOGY-ENHANCED FEEDBACK ENCOURAGING FOR ALL?}

Averagely encouraged with behaviour problems, and the Weakly encouraged contained a sub-category of Weakly encouraged with forgotten matters. Earlier studies indicated possible gendered results (reference deleted to maintain the integrity of the review process; Reinke, et al., 2008), but in this study, profiles for girls and boys were almost identical. Despite the qualitative similarities, there were some quantitative differences between boys and girls; the group of boys receiving negative feedback was bigger and they received feedback more often than girls did, and girls received more positive feedback.

Feedback for pupils with special education needs should be provided to reduce the status of being an at-risk child (Hughes, 2010). However, Tanes and colleagues (2011) have shown that positive technology-enhanced feedback is received mostly by successful students. This study partly confirms their findings as in the groups of Highly encouraged girls (9\%) and boys (11.4\%), the majority were pupils who did not have special education needs. They were also absent relatively rarely. Thus, these pupils may be considered somewhat successful. Only a few teachers seemed to encourage pupils highly in their classroom, as there were approximately around three Highly encouraged pupils in each classroom.

Perceived emotional support from the teacher is important as it is related to higher learning outcomes and fewer problems in school (Tennant, et al., 2015), better motivation and lower stress (Rowe, 2010), better self-esteem (Reddy, et al., 2003), lower anxiety (Hinton, et al., 2012) and higher school engagement (Klem \& Connel, 2004). In our analysis, we identified groups of Averagely encouraged with behaviour problems both for girls ( $0.4 \%)$ and boys $(1.3 \%)$. The boys in this group received almost twice as much feedback ( 46 times) about behaviour problems as girls ( 24 times). These groups received large amount of negative feedback, but also praise, which may be interpreted as an attempt to compensate negative feedback. However, according to Stanton-Chapman and colleagues 


\section{IS TECHNOLOGY-ENHANCED FEEDBACK ENCOURAGING FOR ALL?}

(2016) positive behaviour interventions usually fail as they do not provide the skills for behaving appropriately. Furthermore, Rowe and colleagues (2014) claim that pupils who feel that they have somehow failed usually avoid feedback as they fear receiving negative feedback. Each Averagely encouraged group included more pupils with special education needs than pupils with no support needs, and the effects of the constant negative person-targeted feedback they receive should be considered. From one to three Averagely encouraged girls or boys with behaviour problems studied in a single classroom and whether this has an impact for example on social interaction between peers or risk for other problems should be evaluated, as these profiles received also more notes on absence compared to other profiles.

A large amount of feedback about forgotten homework or supplies was given to Weakly encouraged groups (Weakly encouraged with forgotten matters) of girls (2.6\%) and boys (4.7\%). It is not clear whether feedback about forgotten matters is interpreted as process- or person-targeted. Kluger and Denisi (1996) have written that previous experiences of success and failure shape the way in which one interprets the given feedback. When it is interpreted as process-targeted, it has a positive effect on learning (Dweck \& Master, 2009; Hattie \& Timperlay, 2007), and it may have an impact on adopting a learning approach (Pekrun, et al., 2014). On the other hand, when interpreted as person-targeted, it has harmful effects (Dweck \& Master, 2009; Hattie \& Timperlay; Hughes, 2010). Hughes (2010) warns that pupils at risk of academic failure usually avoid corrective feedback since they perceive it as a negative assessment of themselves. This should be taken into account as there were more pupils with special education needs than others in these groups. Based on these data, the results show that the majority of girls $(82.8 \%)$ and boys $(77.3 \%)$ were encouraged weakly, although they did not receive negative feedback either. 


\section{IS TECHNOLOGY-ENHANCED FEEDBACK ENCOURAGING FOR ALL?}

\subsection{Limitations and future implications}

Several limitations should be considered in relation to this study. The system administrator of the municipality in which the data was collected can modify the predefined feedback options of the platform, and thus, the options may vary between different municipalities. Since these feedback notes were obtained from only one municipality, the current data were not nationally or internationally representative. In the observed municipality, as many as 22.4 percent of pupils needed support in Tiers 2 or 3 , although the number at the national level was 16 percent.

Unexpected large school and class level effects on the dependent variables shed shadow over the generalisability of the findings, but at the same time inform about current unstructured feedback practices. These data consisted of a large amount of feedback related to learning and behaviour during the lesson, but we were not able to compare the notes with the performance of the pupils receiving the notes. Based on the current data, we do not know if technology-enhanced feedback has any connection to learning results, and therefore, further research is needed. The data of this study showed that there are pupils receiving dozens of feedback notes that could be interpreted as either person- or processtargeted. If teacher praise is interpreted as person-targeted, it may have a harmful effect on learning and motivation (Dweck \& Master, 2009; Hattie \& Timperlay, 2007), and it may have an impact on adopting learning avoidance (Pekrun, et al., 2014). With these data, the impact of feedback on learning is impossible to evaluate, and therefore, it is important to study further whether pupils perceive the feedback as person- or process-targeted. Both teachers' and pupils' perspectives of technologyenhanced feedback should be studied more closely, as some teachers perceive that they would need more education to enhance inclusion (Saloviita \& Schaffus, 2016). It would also be important to study the impact of these notes on pupils' perceived well-being, as the core curriculum emphasises the role of encouraging feedback. 


\section{IS TECHNOLOGY-ENHANCED FEEDBACK ENCOURAGING FOR ALL?}

\subsection{Conclusions}

The results of this study do not describe the behaviour of pupils but the feedback practices of teachers. Thus far, no pedagogical guidelines have been set for the use of the platform and therefore, teachers may use the options of this online platform in the way they deem appropriate. Teachers may provide feedback quickly by clicking predefined options as often as they like resulting in a large variation in how the feedback is implemented. Technology-enhanced feedback notes may reflect the fact that against the recommendations, teachers evaluate pupils' personality (Mullola, 2012). Besides, there are still teachers who perceive technology as a threat (Gao, et al., 2017), explaining the variation. Another question is whether technology shapes the way teachers provide feedback, as it has been suggested that the form of the template used has an influence on practices (Severinsson, 2016).

Teachers may feel pressured to document the problems they have with pupils, perhaps as evidence of a need for support for the pupil or support for the teacher in a classroom. From this point of view, the lesson notes described in this study may be understood only as documentation without considering them as person-targeted harmful feedback. However, it would be important to consider carefully the use of predefined notes from the pupils' point of view, as the pupils also have access to read them.

Evaluation of technology-enhanced feedback may give a hint of the face-to-face feedback in the classroom, and feedback practices between teachers may vary in the same way in classroom situations as in online conditions. If students at the university level perceive to need encouraging feedback to support their fragile confidence (Ferguson, 2011), then how about the growing children and adolescents with support needs who may fear being different from their peers in general. Based on the idea of inclusive school for all, feedback should support diverse learners as the way they are; however, current technology-enhanced feedback practices do not meet these requirements. These results confirm that pupils with special needs got more negative feedback than general education students, raising the issue 


\section{IS TECHNOLOGY-ENHANCED FEEDBACK ENCOURAGING FOR ALL?}

whether they are accepted in school the way they are. Thus, it can be summarised that technologyenhanced feedback is not equally encouraging for all. 


\section{IS TECHNOLOGY-ENHANCED FEEDBACK ENCOURAGING FOR ALL? \\ References}

Alcott, B. (2017). Does teacher encouragement influence students' educational progress: a propensityscore matching analysis. Research in Higher Education DOI 10.1007/s11162-017-9446-2.

Acuna, S.R., Rodicio, H.G. \& Sànhez, E. (2010). Fostering active processing of instructional explanations of learners with high and low prior knowledge. European Journal of Psychology Education, 26:435-452.

Cumming, T.M. \& Rodriquez, C.D. (2017). A meta-analysis of mobile technology supporting individuals with disabilities. The Journal of Special Education, 51(3), 164-176.

Dweck, C.S. \& Master, A. (2009). Self-theories and motivation, students' beliefs about intelligence. In K.R. Wentzel \& A. Wickfield (Eds.) Handbook of motivation at school (pp.123-140). New York: Routledge.

ESSA (2015). Every student succeeds act. Retrieved from: https://www.ed.gov/esea

Ferguson, P. (2011). Student perceptions of quality feedback in teacher education. Assessment \& Evaluation in Higher Education, 36 (1), 51-62. DOI: 10.1080/02602930903197883

Gao, Q., Yan, Z., Wei, C., Liang, Y., \& Mo, L. (2017). Three different roles, five different aspects: Differences and similarities in viewing school mobile phone policies among teachers, parents, and students. Computers \& Education 106, 13-25.

Harris, L.R., Brown, G.T.L. \& Harnett, J.A. (2014). Understanding classroom feedback practices: a study of New Zealand student experiences, perceptions, and emotional responses. Educational Assessment, Evaluation and accountability, 26 (2), 107-133. DOI 10.1007/s11092-013-9187-5

Hattie, J. \& Timperley, H. (2007). The Power of Feedback. Review of Educational Research, 77:81. doi: 10.3102/003465430298487 


\section{IS TECHNOLOGY-ENHANCED FEEDBACK ENCOURAGING FOR ALL?}

Hinton, C., Fischer, K.W. \& Glennon, C. (2012). Mind, Brain, and Education. Retrieved from: http://mberesearchengagementframework.org/wp-content/uploads/2016/02/Mind-BrainEducation.pdf

Hoffman, J. (2008). I know what you did last math class. The New York Times, May 4, 2008. Retrieved from: https://mobile.nytimes.com/2008/05/04/fashion/04edline.html

Hotulainen, R. \& Takala, M. (2014). Parents' views on the success of integration of students with special education needs, International Journal of Inclusive Education, 18(2), 140-154. DOI: 10.1080/13603116.2012.759630

Hughes, G.B. (2010). Formative assessment practices that maximize learning for students at risk. In H.L.Andrack \& G.J. Cizek (Eds.) Handbook of formative assessment (pp. 212-232). New York: Routledge.

Kefalidou, G. (2017). When immediate interactive feedback boosts optimization problem solving: a "human-in-the-loop" approach for solving capacitated vehicle routing problems. Computers in Human Behaviour, 73, 110-124. http://dx.doi.org/10.1016/j.chb.2017.03.019

Kluger, A.N. \& DeNisi, A. (1996). The effects of feedback interventions on performance: a historical review, a meta-analysis, and a preliminary feedback intervention theory. Psychological Bulletin, $119,2,254-284$.

Klem, A.M. \& Connel, J.P. (2004). Relationship matter: linking teacher support to student engagement and achievement. The Journal of School Health, 74, 7, 262-273.

Kourkoutas, E. \& Giovazolias, T. (2015). School-based counselling work with teachers: an integrative model. The European Journal of Counselling Psychology 3(2), 137-158. doi:10.5964/ejcop.v3i2.58 


\section{IS TECHNOLOGY-ENHANCED FEEDBACK ENCOURAGING FOR ALL?}

Loibl, K. \& Rummel, N. (2014). Knowing what you don't know makes failure productive. Learning and Instruction, 34, 74-85.

Maggin, D.M., Wehby, J.H., Farmer, T.W., Brooks, D.S. (2016). Intensive interventions for students with emotional and behavioural disorders: issues, theory, and future directions. Journal of Emotional and Behavioral Disorders, 24(3), 127-137. DOI: 10.1177/1063426616661498

Marsh, H.W., Lüdtke, O., Trautwein, U. \& Morin, A.J.S. (2009). Classical latent profile analysis of academic self-concept dimensions: synergy of person- and variable-centered approaches to theoretical models of self-concept. Structural Equation Modelling: A Multidisciplinary Journal, 16: 191-225. DOI:10.1808/10705510902751010

Moore Partin, T.C., Robertson, R.E., Maggin, D.M., Oliver, R.M. \& Wehby, J.H. (2010). Using teacher praise and opportunities to respond to promote appropriate student behavior. Preventing school failure, 54(3), 172-178.

Mullola, S. (2012). Teachability and school achievement. Is student temperament associated with school grades? Unigrafia: Helsinki, ISBN 978-952-10-7866-8 (pdf)

NBE; National Board of Education, (2014). Perusopetuksen opetussuunnitelman perusteet 2014. Retrieved

from: http://www.oph.fi/download/163777_perusopetuksen_opetussuunnitelman_perusteet_2014. pdf

Palts, K. \& Kalmus, V. (2015). Digital channels in teacher-parent communication: The case of Estonia. Education and Development using Information and Communication Technology, 11, 3, 65-81. 


\section{IS TECHNOLOGY-ENHANCED FEEDBACK ENCOURAGING FOR ALL?}

Pekrun, R., Cusack, A., Murayma, K., Elliot, A.J., \& Thomas, K. (2014). The power of anticipated feedback: effect on students' achievement goals and achievement emotions. Learning and Instruction 29, 115-124.

Oberski, D. (2016). Mixture models: latent profile and latent class analysis. In J. Robertson \& M. Kaptein (Eds.) Modern Statistical Methods for HCI (275-287). Switzerland: Springer.

OECD, (2018). PISA 2015, Results in focus. Retrieved from: https://www.oecd.org/pisa/pisa-2015results-in-focus.pdf

Oinas, S., Vainikainen, M.-P., \& Hotulainen, R. (2017). Technology-enhanced feedback for parents and pupils in Finnish basic education. Computers \& Education, 108, 59-70. DOI: 10.1016/j.compedu.2017.01.012

Reddy, R., Rhode, J.E. \& Mulhall, P. (2003). The influence of teacher support on student adjustment in the middle school years: a latent growth study. Development and Psychology, 15, 119-138._DOI: 10.1017.S0954579403000075

Reinke, W.M., Herman, K.C., Petras, H. \& Ialongo, N.S. (2008). Empirically derived subtypes of child academic and behaviour problems: co-occurrence and distal outcomes. Journal of Abnormal Child Psychology, 36: 759-770.

Rowe, A. (2010). The personal dimension in teaching: why students value feedback. International Journal of Educational Management, 25, 4 (343-360). Retrieved from: http://dx.doi.org/10.1108/09513541111136630

Rowe, A., Fitness, J. \& Wood, L.N. (2013). The role and functionality of emotions in feedback at university: a qualitative study. Journal of Australian Educational Research 41:283-309. DOI 10.1007/s13384-013-0135-7 


\section{IS TECHNOLOGY-ENHANCED FEEDBACK ENCOURAGING FOR ALL?}

Ryan, R.M. \& Deci, E. (2009). Promoting self-determined school engagement: motivation, learning and well-being. In K.R. Wentzel \& A. Wickfield (Eds.) Handbook of motivation at school (pp. 171-196). New York: Routledge.

Saloviita, T. \& Schaffus, T. (2016). Teacher attitudes toward inclusive education in Finland and Brandenburg, Germany and the issue of extra work. European journal of Special Needs Education, 31:4, 458-471. DOI: 10.1080/08856257.2016.1194569

Saloviita, T. \& Tolvanen, A. (2017). Outcomes of primary teacher education in Finland: an exit survey. Teaching Education, 28, 2, 211-225.

Severinsson, S. (2016). Documentation for students in residential care: network of relations of human and non-human actants. International Journal of Inclusive Education, 20, 9, 921-933. DOI: $10.1080 / 13603116.2015 .1125532$

Shenke, K., Ruzek, E., Lam, A.C., Karabenick, S.A. \& Eccles, J.S. (2018). To the means and beyond: Understanding variation in students' perceptions of teacher emotional support. Learning \& Instruction, 55, 13-21.

Shin, J., Lee, Y. \& Seo, E. (2017). Effects of feedback on students' achievement goals: Interaction between reference of comparison and regulatory focus. Learning and Instruction, 49, 21-31.

Spivak, A.L. \& Farran, D.C. (2012). First-grade teacher behaviors and children's prosocial actions in classrooms. Early Education and Development, 23: 623-639. DOI:

$10.1080 / 10409289.2011 .566164$

Stanton-Chapman, T.L., Walker, V.L., Voorhees, M.D. \& Snell, M.E. (2016). The evaluation of a three-tier model of positive behaviour interventions and supports for pre-schoolers in Head Start. Remedial and Special Education, 37(6) 333-344. DOI: 10.1177/0741932516629650 


\section{IS TECHNOLOGY-ENHANCED FEEDBACK ENCOURAGING FOR ALL?}

Statistics Finland (2016). Retriewed from: http://www.stat.fi/til/erop/2015/erop_2015_2016-06-

13_tie_001_fi.html

Tanes, Z., Arnold, K.E., King, A.S. \& Remnet, M.A. (2011). Using Signals for appropriate feedback: Perceptions and practices. Computers \& education 57, 2414-2422. DOI:

10.1016/j.compedu.2011.05.016

Taub, D.A., McCord, J.A. \& Ryndak, D.L. (2017) Opportunities to learn for students with extensive support needs: a context of research-supported practices for all in general education classes. The Journal of Special Education 51 (3), 127-137.

Telhaug, A. O., Mediås, O. A., \& Aasen, P. (2006). The Nordic model in education: Education as part of the political system in the last 50 years. Scandinavian Journal of Educational Research, 50(3), $245-283$

Tennant, J.E., Demaray, M.K., Malecki, C.K., Terry, M.N., Clary, M. \& Elzinga, N. (2015). Students' ratings of teacher support and academic and social-emotional well-being. American Psychologist Association 1045-3830/15 http://dx.doi.org/10.1037/spq0000106

Tempelaar, D.T., Rienties, B. \& Giesbers, B. (2015). In search for the most informative data for feedback generations: Learning analytics in a data-rich context. Computers in Human Behavior, 47, 157-167.

Thuneberg, H. (2007). Is a majority enough? Psychological well-being and its regulation to academic and prosocial motivation, self-regulation and achievement at school. University press: Helsinki

Thuneberg, H., Hautamäki, J. \& Hotulainen, R. (2015). Scientific reasoning, school achievement and gender: a multilevel study between and within school effects in Finland. Scandinavian Journal of Educational Research, 59, 3, 337-356. 


\section{IS TECHNOLOGY-ENHANCED FEEDBACK ENCOURAGING FOR ALL?}

Tirri, K. \& Laine, S. (2017). Teacher education in inclusive education. In J. Clandinin \& J. Husu (Eds) International Handbook of Research on Teacher Education (pp. 761-776). LA: SAGE

UNESCO. (1994). The Salamanca statement and framework for action on special needs education.

Retrieved from: http://www.unesco.org/education/pdf/SALAMA_E.PDF

Vainikainen, M.-P. (2014). Finnish primary school pupils' performance in learning to learn assessments: a longitudinal perspective on educational equity. Helsinki: Unigrafia.

Williams, G.A. \& Kibowski, F. (2016). Latent class analysis and latent profile analysis. In L.A. Jason \& D.S. Glenwick (Eds.) Handbook of methodological approaches to community-based research; qualitative, quantitative, and mixed methods (pp. 143-152). Oxford University Press.

Yuan, J. \& Kim, C. (2015). Effective feedback desing using free technologies. Journal of Educational Computing Research, 52(3), 408-434. DOI: 10.1177/0735633115571929 


\section{IS TECHNOLOGY-ENHANCED FEEDBACK ENCOURAGING FOR ALL?}

Appendix 1. School $(\mathrm{N}=38)$ and class $(\mathrm{N}=715)$ level differences between Teacher praise, Forgotten matters, Behaviour problems and Absence.

\begin{tabular}{llrrrr}
\hline & & Estimate & Wald $\boldsymbol{Z}$ & sig. & $\boldsymbol{R}^{\mathbf{2}}$ \\
\hline Teacher praise & School & 172.46 & 4,11 & .000 & .36 \\
& School*Class & 126.11 & 14,98 & .000 & .26 \\
Forgotten matters & School & 13.85 & 3,15 & .002 & .07 \\
& School*Class & 42.73 & 12,44 & .000 & .22 \\
Behaviour problems & School & 1,38 & 3,24 & .001 & .05 \\
& School*Class & 4,61 & 11,53 & .000 & .16 \\
Absence & School & 544.35 & 3,93 & .000 & .16 \\
& School*Class & 346.19 & 9,49 & .000 & .28 \\
\hline
\end{tabular}

Appendix 2. Descriptive statistics of one-way ANOVA and Mann-Whitney U-test with effect sizes.

\begin{tabular}{lrrrrrrrr}
\hline Profiles & Tier & Tier & & & & & & \\
\hline Highly encouraged girls & $\mathbf{0 / 1}$ & $\mathbf{2 / 3}$ & total M & SD & $\boldsymbol{F}$ & sig. & $\boldsymbol{U}$ & $\boldsymbol{n}^{\mathbf{2}}$ \\
Highly encouraged boys & 331 & 11 & .0891 & .28 & 40.062 & .000 & .000 & 1.946 \\
Averagely encouraged girls 1 & 403 & 52 & .1146 & .32 & 83.846 & .000 & .000 & 1.328 \\
Averagely encouraged girls 2 & 31 & 15 & .0120 & .11 & 11.860 & .001 & .001 & 1.108 \\
Averagely encouraged boys & 121 & 42 & .0424 & .20 & 16.534 & .000 & .000 & .733 \\
Averagely encouraged girls with problems & 121 & 100 & .0557 & .23 & 27.281 & .000 & .000 & .709 \\
Averagely encouraged boys with problems & 10 & 7 & .0044 & .07 & 9.515 & .002 & .002 & 1.618 \\
Weakly encouraged girls with forgotten matters & 22 & 28 & .0126 & .11 & 16.842 & .000 & .000 & 1.193 \\
Weakly encouraged boys with forgotten matters & 64 & 32 & .0250 & .16 & 27.266 & .000 & .000 & 1.142 \\
Weakly encouraged girls & 99 & 82 & .0456 & .21 & 22.236 & .000 & .000 & .708 \\
Weakly encouraged boys & 2717 & 459 & .8271 & .38 & 1.207 & .272 & .272 & .055 \\
\hline
\end{tabular}

Note: Pupils according to identified profiles receiving support in Tier $0 / 1$ or Tier $2 / 3$ are presented in columns. Both parametric and non-parametric methods showed statistical differences between the pupils in Tier 0/1 and Tier 2/3 in each profiles except in Weakly encouraged girls/boys. 